\title{
First report of canine ocular thelaziosis by Thelazia callipaeda in Portugal
}

\author{
Lisete Vieira' ${ }^{1}$, Filipa T Rodrigues ${ }^{2}$, Álvaro Costa ${ }^{1}$, Duarte Diz-Lopes² ${ }^{2}$ João Machado ${ }^{3}$, Teresa Coutinho ${ }^{4}$, \\ Joana Tuna', Maria Stefania Latrofa ${ }^{5}$, Luís Cardoso ${ }^{4,6^{*}}$ and Domenico Otranto ${ }^{5}$
}

Background: Thelazia callipaeda eyeworms are transmitted by the non-biting insect vector Phortica variegata in Europe and infest the conjunctiva(s) of several mammalians, including dogs and humans. Infested hosts might remain asymptomatic or display clinical manifestations characterized by variable degrees of severity.

Methods: From July to November 2011, nine dogs were detected with eyeworms at two veterinary clinics in Chaves and Bragança (North of Portugal). Nematodes collected from dogs were morphologically and molecularly characterized at species level.

Results: Nematodes were identified as T. callipaeda. The number of worms collected from each dog ranged from three to 76 (average $=17.9 \pm 26.8$ ) and was not associated with the severity of clinical signs. Ocular discharge and conjunctivitis were observed in all dogs and ocular pruritus occurred in six of them. Polymerase chain reaction and sequencing of a portion of target cytochrome $c$ oxidase subunit 1 gene further identified all nematodes as haplotype 1.

Conclusions: This is the first report of T. callipaeda and associated ocular disease in dogs from Portugal, suggesting that thelaziosis should be included in the differential diagnosis of canine ocular affections. The risk of the infestation spreading from Spain and France to Portugal, through domestic dogs or wild mammals, is realistic.

\section{Background}

Several species of Thelazia parasitic nematodes (Spirurida, Thelaziidae) have been reported to infest cattle and/or equids (e.g., Thelazia gulosa, Thelazia lachrymalis, Thelazia rhodesi and Thelazia skrjabini), domestic and wild carnivores, as well as humans, worldwide (e.g., Thelazia californiensis, Thelazia callipaeda) [1]. While the occurrence of $T$. californiensis is limited to western areas of the United States of America [2], T. callipaeda is widely distributed in far eastern countries and throughout Europe. These nematodes are transmitted by non-biting insect vectors and can be found in the conjunctiva(s) of vertebrate hosts [1].

A fruitfly species of the subfamily Steganinae, i.e. Phortica variegata, is the recognized intermediate host of $T$. callipaeda in Europe [3,4]. This insect transmits $T$. callipaeda third-stage larvae while feeding on ocular

\footnotetext{
* Correspondence: Icardoso@utad.pt

${ }^{4}$ Department of Veterinary Sciences, University of Trás-os-Montes e Alto

Douro, Vila Real, Portugal

${ }^{6}$ Parasite Disease Group, Instituto de Biologia Molecular e Celular,

Universidade do Porto, Oporto, Portugal

Full list of author information is available at the end of the article
}

secretions around the eyes of a vertebrate receptive host (e.g. humans and other mammals, such as dogs and cats). Both the larvae and adults are involved in the pathogenesis of ocular disease caused by T. callipaeda, which is characterized by clinical manifestations ranging from ocular pruritus, lacrimation, congestion and discharge, epiphora, exudative conjunctivitis, corneal edema to keratitis and corneal ulceration in severe cases $[1,5]$. Treatment protocols include (i) mechanical removal of worms and (ii) administration of macrocyclic lactones, including ivermectin, milbemycin oxime and moxidectin $[6,7]$.

For its original distribution (former Soviet republics, India, Thailand, China and Japan), T. callipaeda was commonly referred to as the "oriental eyeworm" [2]. However, over the last decade, infestations by $T$. callipaeda have been reported in dogs, humans, cats, foxes, rabbits and/or wolves in Italy [8,9], Germany [10], France [11,12], Switzerland [13] and Spain [14]. A thorough molecular examination of the nucleotide sequence of the mitochondrion cytochrome oxidase subunit 1 ( $\operatorname{cox} 1)$ gene revealed the existence of seven distinct haplotypes of T. callipaeda 
in Asia, but only haplotype 1 (h1) and another yet suggested novel unnamed haplotype in Europe $[10,15]$. The evidence of one unique haplotype circulating in Europe, irrespective of the several host species from which the nematodes had been collected, led to the hypothesis that the populations of $T$. callipaeda in Europe are strictly associated with the species of arthropod vector [15].

Climatic changes, including global warming, together with the increased movement of domestic animals across European countries, are facilitating the spread of several vector-borne pathogens in previously naive countries, thus increasing the risk of infections in animals and humans [16]. Current methods for disease mapping have identified large areas of Europe which are characterized by suitable climatic conditions for the development of both $P$. variegata and T. callipaeda [4].

This report describes the first occurrence of ocular thelaziosis by T. callipaeda in Portugal and provides hypotheses on the mechanisms that are leading to an increment of reports of this parasitosis and possible risks for public health.

\section{Methods}

\section{Animals and samples}

From July to November 2011, nine dogs were detected with worms in their conjunctivas at two veterinary medical centers in the cities of Chaves $(n=6)$ and Bragança $(\mathrm{n}=3)$, (North of Portugal). These dogs lived in a geographical area of $\sim 2,460 \mathrm{~km}^{2}$ consisting of the contiguous municipalities of Chaves, Vinhais and Bragança (Figure 1) and had never travelled abroad. All animals were in good body condition but were referred to the practice due to an ocular discharge. After administration of an ocular anaesthetic (oxibupocraine hydrochloride, Anestocil ${ }^{\circledR}$ ), an ophthalmic examination was performed and worms were collected from the conjunctivas using sterile cotton swabs or flushing with saline solution
( $\mathrm{NaCl} 0.9 \%$ ) (Figure 2). Data on breed, gender, age and habitat were recorded for each animal (Table 1).

\section{Parasite identification}

Worms collected from each individual dog were morphologically identified to species and gender according to keys proposed by Otranto et al. [17]. Gender was assigned based on the position of the vulva anterior to the oesophagus-intestinal junction (females) and presence of five pairs of postcloacal papillae (males) [18]. Worms were then counted (Table 1) and stored in $70 \%$ ethanol until molecular analyses. Parasite samples were subjected to specific PCR amplification of a portion (689 bp) of the cox1 gene [15]. Amplicon sequences were determined in both directions (using the same primers individually as for the PCR) by visual inspection of the individual electropherograms. Sequences were aligned using the ClustalX program [19] and the alignments were compared with sequences available in public databases for the cox 1 of $T$. callipaeda.

\section{Results}

Table 1 presents data on the identification of the dogs and number of parasites recovered. Affected dog breeds/ crosses were Labrador Retriever, crossbreeds, "Podengo Português" (Portuguese Podengo) and "Cão de Gado Transmontano" (Transmontano Mastiff), aged from 2 to 10 years, both females and males. Besides ocular discharge, conjunctivitis was observed in all dogs, and ocular pruritus in six of them (cases nos. 1, 2, 4, 5, 8 and 9). No apparent association was observed between worm burden and severity of clinical signs. The number of worms collected per dog ranged from three (all female parasites) to 76 ( 51 females and 25 males). The average number of $T$. callipaeda worms counted in the nine infested dogs was 17.9 ( \pm 26.8 SD). The morphological identification was confirmed by specific molecular

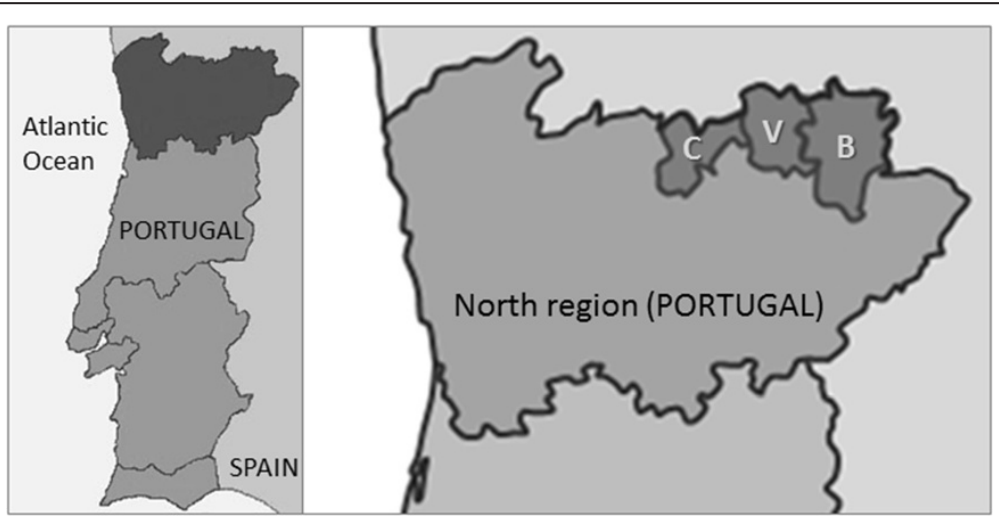

Figure 1 Geographical areas in Portugal from where cases were detected. Dogs found infested with Thelazia callipaeda lived in the contiguous municipalities of Chaves (C), Vinhais $(V)$ and Bragança (B). 


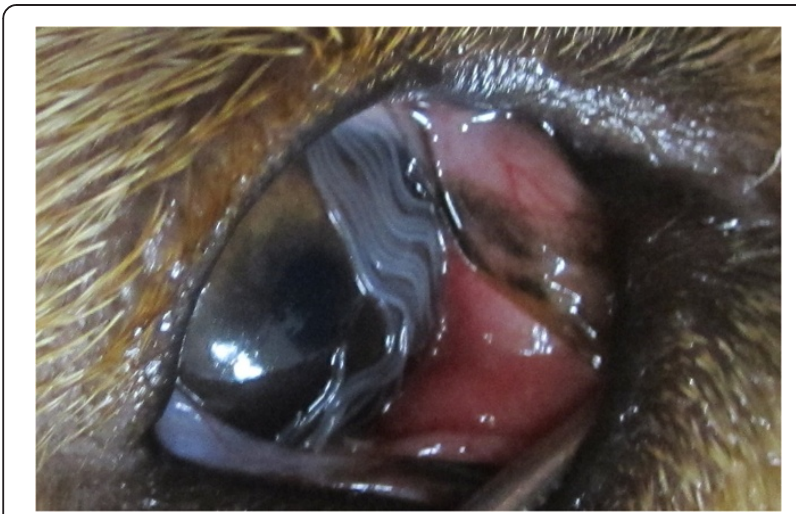

Figure 2 Dog's eye with worms. Several Thelazia callipaeda nematodes in the conjunctiva of a dog (case no. 9).

identification and only h1 nematodes were identified from all the nine dogs.

\section{Discussion}

The present study reports the first autochthonous cases of infestation with T. callipaeda in dogs from Portugal. Indeed, none of the nine dogs had ever travelled abroad. Interestingly, all T. callipaeda nematodes were identified as h1, thus far the only characterized haplotype reported in Europe. All infested animals lived outdoors at high risk of infestation.

This study involved dogs permanently living in the municipalities of Chaves, Vinhais and Bragança, which lie on the Portuguese-Spanish border. Latitude (between $41^{\prime} 00^{\prime \prime}$ and $48^{\prime} 00^{\prime \prime} \mathrm{N}$ ), climate, altitude and vegetation are similar to those of other European countries and regions where thelaziosis is now considered endemic, e.g. Italy [20,21], France [11,12] and Spain [14]. The geographical area of Chaves, Vinhais and Bragança is characterized by a rural environment with many hunting and shepherd dogs, as well as habitats suitable for the development of $P$. variegata. This scenario is in accordance with the observations collected using a predictive geoclimatic model, which identified this area as suitable for the life cycle of the intermediate host [4]. Although the vector of T. callipaeda in northern Portugal is most likely $P$. variegata [4], further studies are required to confirm this hypothesis. Since the nine affected dogs had never travelled abroad, it is presumed that the infestations were of autochthonous origin.

In the Spanish provinces of Orense and Salamanca, 135 and nine cases of canine thelaziosis have been described, respectively [22]. The fact that these provinces are contiguous with the North of Portugal (Orense to the north and Salamanca to the east) supports the hypothesis that this infestation might also be emerging in this country. The existence of a sylvatic life cycle in wild animals, such as foxes and wolves, could be responsible for the spread of the parasite across Europeans countries, because these animals can freely roam through borders and act as reservoirs for this nematode [1]. Under these circumstances, the risk of a spread of the infestation from Spain to Portugal is realistic, for instance through domestic dogs or wild mammals. Moreover, during summer months, a large number of emigrants return home for vacations with their pets from regions of southern and central France where ocular thelaziosis is endemic $[11,12]$. In association with the spread of the infestation from Spain, this could provide an additional explanation for the emergence of $T$. callipaeda in Portugal.

Infestations with $T$. callipaeda are spreading across Europe and becoming a serious problem in several countries. In Italy, T. callipaeda infests around $60 \%$ of dogs in Potenza, Basilicata [8]. In the region of La Vera, Spain, the prevalence of infestation reached almost $40 \%$ in the canine population [14]. Being limited to clinically suspect cases referred to the two veterinary centers, our report does not allow an estimation of the prevalence of

Table 1 Data on the identification of the dogs $(n=9)$ and parasite counts

\begin{tabular}{|c|c|c|c|c|c|c|}
\hline Dogs & & & & & & Worms \\
\hline Case & Breed & Gender & Age (years) & Municipality & Habitat & $F: M(n)$ \\
\hline 1 & Portuguese Podengo & M & 5 & Chaves & Out $(A, C, \operatorname{Pr})$ & $6: 1$ \\
\hline 2 & Crossbreed & M & 2 & Chaves & In/Out $(A, V)$ & $4: 2$ \\
\hline 3 & Transmontano Mastiff & M & 10 & Bragança & Out (ND) & $22: 3$ \\
\hline 4 & Labrador Retriever & M & 2 & Chaves & In/Out (A, PC, Pr) & $3: 1$ \\
\hline 5 & Labrador Retriever & M & 3 & Chaves & In/Out (A, PC, Pr) & $4: 0$ \\
\hline 6 & Portuguese Podengo & $\mathrm{F}$ & 5 & Vinhais & Out $(A, \operatorname{Pr})$ & $3: 0$ \\
\hline 7 & Labrador Retriever & $\mathrm{F}$ & 10 & Bragança & Out (ND) & $41: 19$ \\
\hline 8 & Transmontano Mastiff & M & 9 & Chaves & Out (ND) & $51: 25$ \\
\hline 9 & Crossbreed & $\mathrm{F}$ & 3 & Chaves & Out (ND) & $23: 6$ \\
\hline
\end{tabular}

A: apple trees; C: cherry trees; F: female; In: indoors; M: male; ND: not defined; Out: outdoors; Pc: peach trees; Pr: pear trees; V: vineyards. 
T. callipaeda infestation in the Portuguese canine population to be made. Nevertheless, the number of clinical cases of canine thelaziosis diagnosed from July to November 2011 in the two veterinary clinics involved in this study (i.e. 16 clinical cases out of 2300 dogs brought in for general veterinary consultation) allows an approximate estimation of disease prevalence (i.e. $0.7 \%$ ). This projection includes seven additional cases of canine thelaziosis not described in the Methods, Results and Table 1, which were diagnosed only based on clinical presentation and morphological identification of the nematodes collected (unpublished results).

The low estimated prevalence of infestation detected in the present study might be due to the fact that only dogs presenting clinical signs were examined. Thus, it is possible that a considerable number of asymptomatic dogs are also infested. A recent introduction of T. callipaeda in Portugal may also account for this estimated low prevalence. The investigation in the region of La Vera revealed that the proportion of infested dogs presenting clinical signs $(\sim 15 \%)$ was considerably lower than that recorded in apparently healthy infested dogs ( 85 \%) [14]. Under laboratory conditions the transplantation of adult worms into rabbit eyes induced a severe inflammatory response 3-5 hours post-infestation; however, the clinical signs gradually diminished after one week [23]. These findings might contribute to explaining the high number of asymptomatic but infested animals observed in some studies and a similar scenario may also occur in the North of Portugal.

Up until now, there have only been four reported cases of human infestation with T. callipaeda in Europe, two from Italy and two from France [24]. However, in the last two decades the number of cases of human ocular thelaziosis by $T$. callipaeda in Asian countries has increased [5]. Therefore, it is possible that the number of humans infested in Europe may rise in the future. Due to the potential risk of human infestation, an improved awareness of veterinarians and medical ophthalmologists for this parasite is warranted. In order to control zoonotic eyeworm infestation, correct diagnosis and treatment of infestations in domestic animals are crucial. The administration of broad spectrum macrocyclic lactones on a regular basis as a preventative measure against canine thelaziosis is advisable [18].

\section{Conclusions}

The present report provides the first description of T. callipaeda in dogs from Portugal. Thelaziosis should be included in the list of differential diagnoses in dogs with ocular manifestations. Epidemiological studies of T. callipaeda infestation in dog populations, including both clinically affected and asymptomatic animals, are needed in the northern as well as in the southern regions of Portugal. Addressing these gaps in knowledge will assist the definition of endemic areas and allow the establishment of more effective prophylactic and therapeutic measures against ocular thelaziosis.

\section{Competing interests}

The authors declare that they have no competing interests.

\section{Acknowledgements}

The authors thank Dr. I. Silva (Os Bichos Veterinary Clinic) for help with sample collection, Prof. P. Rodrigues and Dr. J. Requicha (Department of Veterinary Sciences, University of Trás-os-Montes e Alto Douro) for assistance with map design, and Dr. C. Cantacessi (Queensland Tropical Health Alliance, James Cook University, Australia) for a general review of the manuscript. Publication of this article has been sponsored by Bayer Animal Health $\mathrm{GmbH}$.

\section{Author details}

${ }^{1}$ Os Bichos Veterinary Clinic, Chaves, Portugal. ${ }^{2}$ Dr. Duarte Diz-Lopes Veterinary Clinic, Bragança, Portugal. ${ }^{3}$ Veterinary Teaching Hospital, University of Trás-os-Montes e Alto Douro, Vila Real, Portugal. ${ }^{4}$ Department of Veterinary Sciences, University of Trás-os-Montes e Alto Douro, Vila Real, Portugal. ${ }^{5}$ Department of Veterinary Public Health, Faculty of Veterinary Medicine, University of Bari, Bari, Italy. ${ }^{6}$ Parasite Disease Group, Instituto de Biologia Molecular e Celular, Universidade do Porto, Oporto, Portugal.

\section{Authors' contributions}

Collected and characterized clinical samples: LV, FTR, AC, DD-L, JM and JT. Coordinated the study: LC. Performed morphological analysis: TC and MSL. Performed molecular analysis: MSL and DO. Analyzed data, drafted and revised the manuscript: LV, FTR, LC and DO. All authors read and approved the final version of the manuscript.

Received: 24 April 2012 Accepted: 21 June 2012

Published: 21 June 2012

\section{References}

1. Otranto D, Traversa D: Thelazia eyeworm: an original endo- and ectoparasitic nematode. Trends Parasitol 2005, 21:1-4.

2. Anderson RC: Nematode parasites of vertebrates: their development and transmission. Wallingford: CABI Publishing; 2000:404-407.

3. Otranto D, Lia RP, Cantacessi C, Testini G, Troccoli A, Shen JL, Wang ZX: Nematode biology and larval development of Thelazia callipaeda (Spirurida, Thelaziidae) in the drosophilid intermediate host in Europe and China. Parasitology 2005, 131:847-855.

4. Otranto D, Brianti E, Cantacessi C, Lia RP, Máca J: The zoophilic fruitfly Phortica variegata: morphology, ecology and biological niche. Med Vet Entomol 2006, 20:358-364.

5. Shen J, Gasser RB, Chu D, Wang Z, Yuan X, Cantacessi C, Otranto D: Human thelaziosis - a neglected parasitic disease of the eye. J Parasitol 2006, 92:872-875.

6. Bianciardi P, Otranto D: Treatment of dog thelaziosis caused by Thelazia callipaeda (Spirurida, Thelaziidae) using a topical formulation of imidacloprid $10 \%$ and moxidectin 2.5\%. Vet Parasitol 2005, 129:89-93.

7. Ferroglio E, Rossi L, Tomio E, Schenker R, Bianciardi P: Therapeutic and prophylactic efficacy of milbemycin oxime (Interceptor) against Thelazia callipaeda in naturally exposed dogs. Vet Parasitol 2008, 154:351-353.

8. Otranto D, Ferroglio E, Lia RP, Traversa D, Rossi L: Current status and epidemiological observation of Thelazia callipaeda (Spirurida, Thelaziidae) in dogs, cats and foxes in Italy: a "coincidence" or a parasitic disease of the Old Continent? Vet Parasitol 2003, 116:315-325.

9. Otranto D, Cantacessi C, Mallia E, Lia RP: First report of Thelazia callipaeda (Spirurida, Thelaziidae) in wolves in Italy. J Wildl Dis 2007, 43:508-511.

10. Magnis J, Naucke TJ, Mathis A, Deplazes P, Schnyder M: Local transmission of the eye worm Thelazia callipaeda in southern Germany. Parasitol Res 2010, 106:715-717.

11. Dorchies P, Chaudieu G, Simeon LA, Cazalot G, Cantacessi C, Otranto D: First reports of autochthonous eyeworm infection by Thelazia callipaeda (Spirurida, Thelaziidae) in dogs and cat from France. Vet Parasitol 2007, 149:294-297.

12. Ruytoor $P$, Dean $E$, Pennant $O$, Dorchies $P$, Chermette $R$, Otranto D, Guillot J: Ocular thelaziosis in dogs, France. Emerg Infect Dis 2010, 16:1943-1945. 
13. Malacrida F, Hegglin D, Bacciarini L, Otranto D, Nägeli F, Nägeli $C$, Bernasconi C, Scheu U, Balli A, Marenco M, Togni L, Deplazes P, Schnyder M: Emergence of canine ocular thelaziosis caused by Thelazia callipaeda in southern Switzerland. Vet Parasitol 2008, 157:321-327.

14. Miró G, Montoya A, Hernández L, Dado D, Vázquez MV, Benito M, Villagrasa M, Brianti E, Otranto D: Thelazia callipaeda infection in dogs: a new parasite for Spain. Parasit Vectors 2011, 27:148.

15. Otranto D, Testini G, De Luca F, Hu M, Shamsi S, Gasser RB: Analysis of genetic variability within Thelazia callipaeda (Nematoda: Thelazioidea) from Europe and Asia by sequencing and mutation scanning of the mitochondrial cytochrome $c$ oxidase subunit 1 gene. Mol Cell Probes 2005, 19:306-313.

16. Baneth G, Bourdeau P, Bourdoiseau G, Bowman D, Breitschwerdt E, Capelli G, Cardoso L, Dantas-Torres F, Day M, Dedet JP, Dobler G, Ferrer L, Irwin P, Kempf V, Kohn B, Lappin M, Little S, Maggi R, Miro G, Naucke T, Oliva G, Otranto D, Penzhorn B, Pfeffer M, Roura X, Sainz A, Shaw S, Shin S, SolanoGallego L, Straubinger R, Traub R, Trees A, Truyen U, Demonceau T, Fitzgerald R, Gatti D, Hostetler J, Kilmer B, Krieger K, Mencke N, Mendao C, Mottier L, Pachnicke S, Rees B, Siebert S, Stanneck D, Tarancon Mingote M, von Simson C, Weston S: Vector-Borne Diseases - constant challenge for practicing veterinarians: recommendations from the CVBD World Forum. Parasit Vectors 2012, 5:55.

17. Otranto D, Lia RP, Traversa D, Giannetto S: Thelazia callipaeda (Spirurida, Thelaziidae) of carnivores and humans: morphological study by light and scanning electron microscopy. Parassitologia 2003, 45:125-133.

18. Otranto D, Eberhard ML: Zoonotic helminths affecting the human eye. Parasit Vectors 2011, 4:41.

19. Thompson JD, Gibson TJ, Plewniak F, Jeanmougin F, Higgins DG: The Clustal $X$ windows interface: flexible strategies for multiple sequence alignment aided by quality analysis tools. Nucleic Acids Res 1997, 24:4876-4882

20. Otranto D, Dantas-Torres F, Mallia E, DiGeronimo PM, Brianti E, Testini G, Traversa D, Lia RP: Thelazia callipaeda (Spirurida, Thelaziidae) in wild animals: report of new host species and ecological implications. Vet Parasitol 2009, 166:262-267.

21. Otranto D, Dantas-Torres F: Canine and feline vector-borne diseases in Italy: current situation and perspectives. Parasit Vectors 2010, 3:2

22. Bello-Gavete A, Hernandéz-Martínez L, Checa-Herraiz R, Dado-Ortiz D, Montoya-Matute A, Benito-Hidalgo M, Vázquez M, Villagrasa M, Miró Corrales G: Situación epidemiológica actual de la thelaziosis ocular canina en España. Madrid: Proceedings of the 28th Annual Meeting of AMVAC; 2012.

23. Wang ZX, Yang ZX: Experimental observations on the biological features and pathogenicity of Thelazia callipaeda parasitized in rabbits. Chin J Parasitol Parasitic Dis 1985, 3:128-130.

24. Otranto D, Dutto M: Human thelaziasis, Europe. Emerg Infect Dis 2008 14:647-649.

doi:10.1186/1756-3305-5-124

Cite this article as: Vieira et al:: First report of canine ocular thelaziosis by Thelazia callipaeda in Portugal. Parasites \& Vectors 2012 5:124.

\section{Submit your next manuscript to BioMed Central and take full advantage of:}

- Convenient online submission

- Thorough peer review

- No space constraints or color figure charges

- Immediate publication on acceptance

- Inclusion in PubMed, CAS, Scopus and Google Scholar

- Research which is freely available for redistribution

Submit your manuscript at www.biomedcentral.com/submit
C Biomed Central 